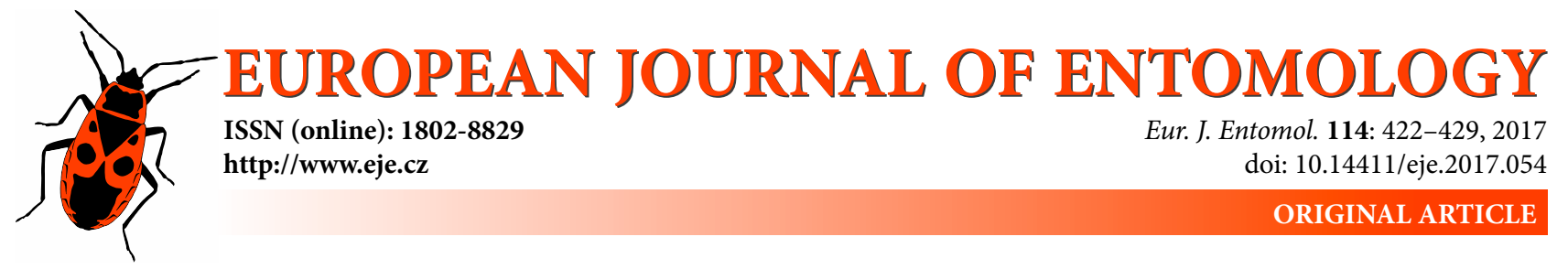

\title{
First mitogenome for the subfamily Miltogramminae (Diptera: Sarcophagidae) and its phylogenetic implications
}

\author{
LIPING YAN ${ }^{1,2}$, Ming ZHANG ${ }^{1}$, YunYun GAO ${ }^{1}$, Thomas PAPE ${ }^{2}$ and Dong ZHANG ${ }^{1, *}$ \\ ${ }^{1}$ School of Nature Conservation, Beijing Forestry University, Beijing, China; e-mails: yanlp523@qq.com, zmbjfu@163.com, \\ 424208072@qq.com, ernest8445@163.com \\ ${ }^{2}$ Natural History Museum of Denmark, University of Copenhagen, Copenhagen, Denmark; e-mail: tpape@snm.ku.dk
}

Key words. Diptera, Calyptratae, Sarcophagidae, Miltogramminae, mitogenome, flesh fly, phylogeny

\begin{abstract}
The mitochondrial genome of Mesomelena mesomelaena (Loew, 1848) is the first to be sequenced in the flesh fly subfamily Miltogramminae (Diptera: Sarcophagidae). The 14,559 bp mitogenome contains 37 typical metazoan mitochondrial genes: 13 protein-coding genes, two ribosomal RNA genes and 22 transfer RNA genes, with the same locations as in the insect ground plan. All the protein-coding genes have the start codon ATN, except for cox1 (TCG). Eight protein-coding genes have the stop codon TAA, while the remaining five have the stop codon T ( $\operatorname{cox} 1, \operatorname{cox} 2$, nad5, and nad4) or TAG (cytb). Synonymous and non-synonymous substitution rates (Ks and $\mathrm{Ka}$ ) for each protein-coding gene indicate that these genes evolved primarily under negative (or purifying) selection (Ka $<\mathrm{Ks}$ ). Phylogeny of Sarcophagidae is proposed based on all the sarcophagid mitogenomes in GenBank, and the subfamily topology is reconstructed as (Sarcophaginae (Paramacronychiinae, Miltogramminae)).
\end{abstract}

\section{INTRODUCTION}

With 3000 described species worldwide (Pape et al., 2011), the Sarcophagidae (Diptera: Calyptratae), also known as flesh flies, are generally subdivided into three subfamilies, Miltogramminae, Paramacronychiinae and Sarcophaginae (Pape, 1996; Piwczyński et al., 2017). It is a young lineage within the schizophoran super-radiation of Diptera (Wiegmann et al., 2011; Cerretti et al., 2017) with diverse life habits, e.g. kleptoparasitism of Hymenoptera (Spofford et al., 1989), predators of other insects, spider egg sacs and reptile eggs (Pickens, 1981; Lopes, 1982; Mullen et al., 1984; Trauth \& Mullen, 1990; Pape, 1996), parasitoids of insects and snails (Pape, 1994; McKillup et al., 2000; Stucky, 2015) and necro/coprophagy (Bänziger $\&$ Pape, 2004). Thus, the Sarcophagidae are of important ecological, medical and forensic importance. Mitochondrial genomes (mitogenomes) are thought to be reliable markers for phylogeny reconstruction and taxonomic diagnosis (Nelson et al., 2012; Cameron, 2014). Here we document the nearly-complete mitogenome of Mesomelena mesomelaena (Loew, 1848) (Figs 1-2), which is the first nearlycomplete mitogenomic data for the Miltogramminae and we reconstruct the phylogeny of the Sarcophagidae based on all the mitogenomes in GenBank.

\section{MATERIALS AND METHODS}

Two dry specimens of M. mesomelaena, whole body of one specimen (collected in 2014), thorax of another (collected in 2015, voucher BFU-06574), were used for DNA extraction using a QIAGEN DNeasy ${ }^{\circledR}$ Blood and Tissue Kit (Qiagen, Hilden, Germany). The mitogenome was amplified in overlapping fragments by 18 primer pairs (Weigl et al., 2010; Zhang et al., 2013) and a pair of specific primers designed from sequenced fragments (Table 1). The PCR was performed in a reaction volume of $25 \mu \mathrm{L}$, which contained $1 \mu \mathrm{L}$ of genome DNA, $1 \mu \mathrm{L}$ of each primer (10 $\mu \mathrm{M}), 2.5 \mu \mathrm{L}$ of $10 \times$ Es Taq PCR Buffer (Beijing Cowin Biosciencee Co., Ltd., China), $2 \mu \mathrm{L}$ of dNTPs mixture (2.5 mM each) (Beijing Cowin Biosciencee Co., Ltd., China), $0.3 \mu \mathrm{L}$ Es Taq DNA Polymerase (1.5 U) (Beijing Cowin Biosciencee Co., Ltd., China) and $17.2 \mu \mathrm{L}$ sterling double distilled water. The PCR cycles for all amplifications were the same as used by Zhang et al. (2016b). Products were resolved in 1\% agarose gels and stained with Gold View (Beijing Cool Technology Co., Ltd., China), then purified and sequenced bidirectionally by BGI Sequencing (Beijing, China). After assembly of raw sequences by SeqMan (DNAStar, Steve ShearDown, 1998-2001 version DNASTAR Inc., USA), the annotation of the mitogenome was performed as described in Zhang et al. (2016b). The mitogenome map was produced using CGView (Grant \& Stothard, 2008).

All the mitochondrial genomes of Sarcophagidae in GenBank were included in the present study, except for two sequences: one with locus KP861920 [stated to be Sarcophaga crassipalpis],

\footnotetext{
* Corresponding author; e-mail: ernest8445@163.com
} 


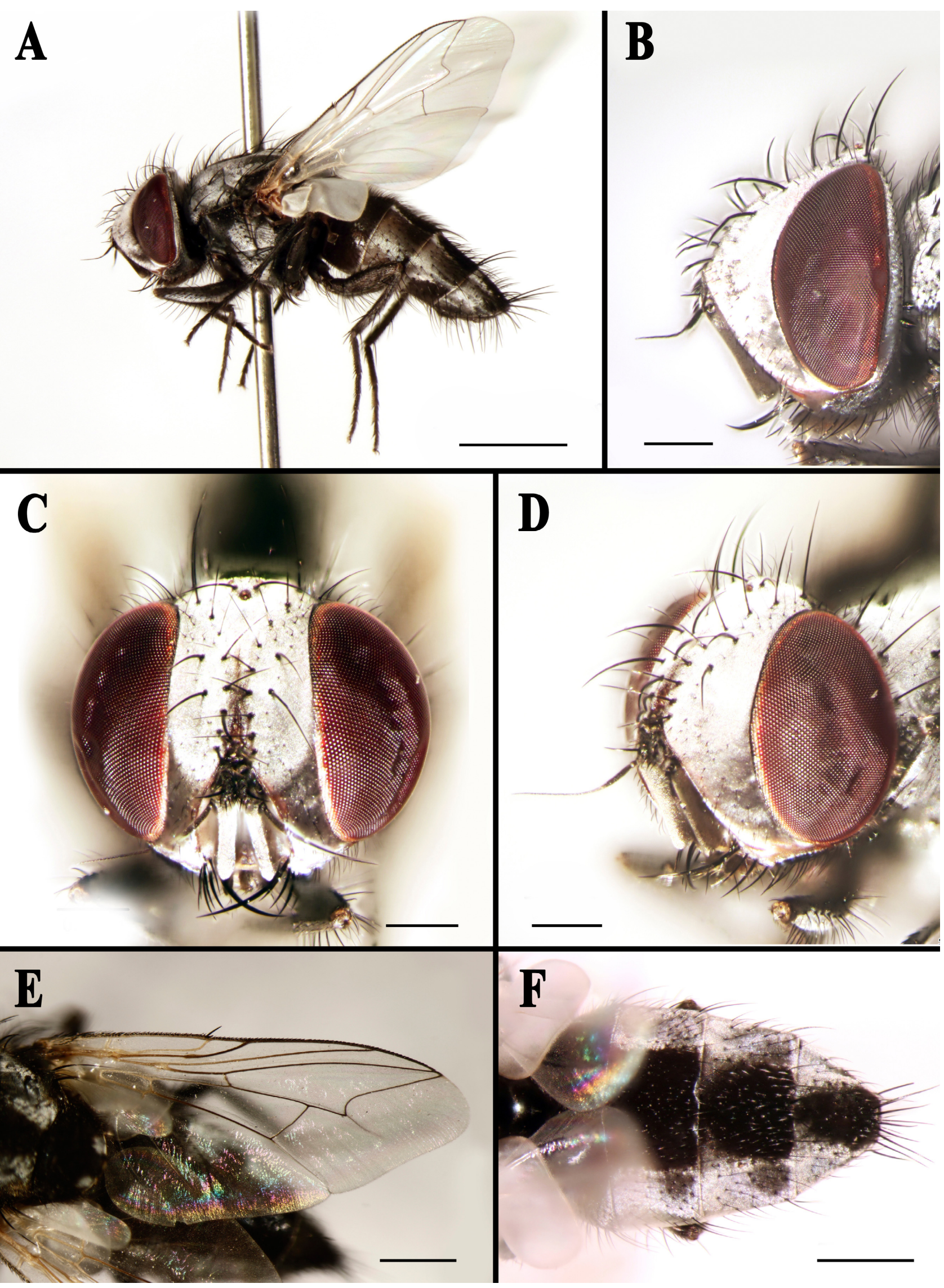

Fig. 1. Mesomelena mesomelaena (Loew, 1848), male. A - habitus, lateral view; B - head, lateral view; C - head, anterior view; D - head, anterolateral view; $\mathrm{E}-$ right wing, dorsal view; F-abdomen, dorsal view. Scales: A - $2 \mathrm{~mm}, \mathrm{~B}-\mathrm{D}-0.5 \mathrm{~mm}, \mathrm{E}$ and $\mathrm{F}-0.5 \mathrm{~mm}$. 


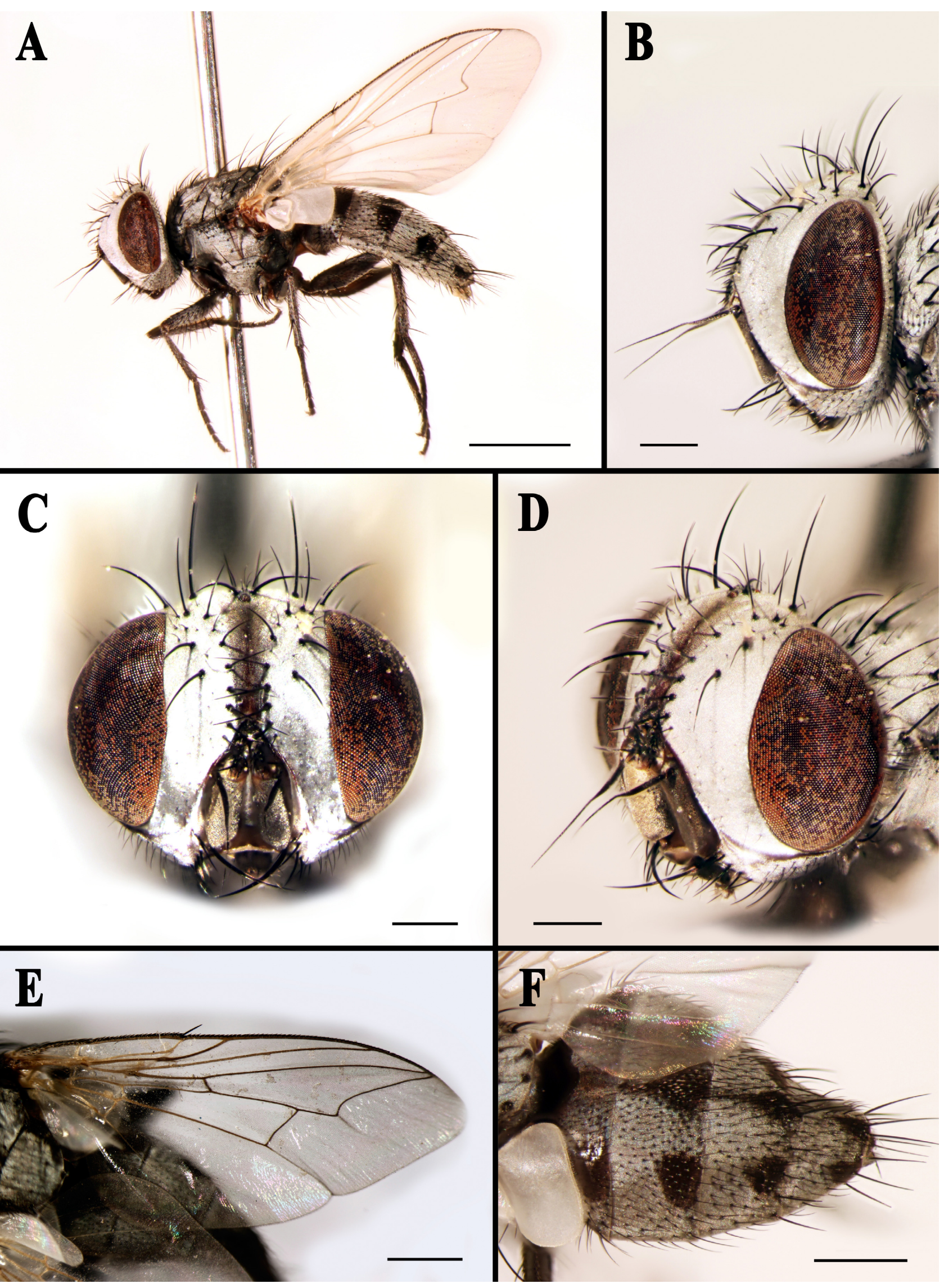

Fig. 2. Mesomelena mesomelaena (Loew, 1848), female. A - habitus, lateral view; B - head, lateral view; C - head, anterior view; D head, anterolateral view; E - right wing, dorsal view; F - abdomen, dorsal view. Scales: A - 2 mm, B-D - 0.5 mm, E and F-0.5 mm. 
Table 1. Primer pairs used to amplify the mitogenome of Mesomelena mesomelaena (Loew, 1848).

\begin{tabular}{|c|c|c|c|}
\hline Primers & Sequence $\left(5^{\prime}-3^{\prime}\right)$ & $\begin{array}{l}\text { Size } \\
\text { (bp) }\end{array}$ & Reference \\
\hline 0006_F/R & $\begin{array}{l}\text { TGAATTGCCTGATAAAAGG } \\
\text { CTCCAATTAAAGCTCCTGGATG }\end{array}$ & $\sim 1500$ & Weigl et al., 2010 \\
\hline 0007_F/R & $\begin{array}{l}\text { GGTGGATTACCCCCATTTTTAGG } \\
\text { TTAGCTAAAATTACTCCAGTTAATCCTCC }\end{array}$ & $\sim 1400$ & Weigl et al., 2010 \\
\hline 0008_F/R & $\begin{array}{l}\text { GAGGAGATCCAATTCTCTATCAACA } \\
\text { CAATGACAATTGGTATAAAGCTGTG }\end{array}$ & $\sim 1400$ & Weigl et al., 2010 \\
\hline 0009_F/R & $\begin{array}{l}\text { CATTTGATTTGCATTCAAAAAGTATTG } \\
\text { GCTGCTATAGCAGCTCCTACKCC }\end{array}$ & $\sim 1200$ & Weigl et al., 2010 \\
\hline 0010_F/R & $\begin{array}{l}\text { CCATAAGTAGAAATATAAGGTATAAATCA } \\
\text { TATTGATTTGTGGTATCAAAGATAAG }\end{array}$ & $\sim 1450$ & Weigl et al., 2010 \\
\hline 0011_F/R & $\begin{array}{l}\text { CAGTAATTTTATTAACATGAATTGGAGC } \\
\text { GCGACCTCGATGTTGGATTAAG }\end{array}$ & $\sim 1350$ & Weigl et al., 2010 \\
\hline 0013_F/R & $\begin{array}{l}\text { TTCACTTCAAGATAGCTCATCTCCT } \\
\text { GGTCATGGACTATAYTCTACTA }\end{array}$ & $\sim 1600$ & Weigl et al., 2010 \\
\hline 0014_F/R & $\begin{array}{c}\text { GCAGTTCGATTAACAGCWAA } \\
\text { AGTGATAAGCCTCTTTTTGGCTTC }\end{array}$ & $\sim 1500$ & Weigl et al., 2010 \\
\hline 0016_F/R & $\begin{array}{l}\text { CAATTCTATTAATTAAAGAAATTTCTCC } \\
\text { CTTATTTTTGATTTACAAGACCAATG }\end{array}$ & $\sim 1400$ & Weigl et al., 2010 \\
\hline 0018_F/R & $\begin{array}{l}\text { CCTTTACGAATYAAACACCC } \\
\text { CTATCTTATGTTTTCAAAACATATGC }\end{array}$ & $\sim 1150$ & Weigl et al., 2010 \\
\hline 0019_F/R & $\begin{array}{l}\text { CTAAATTTATTGCACTAATCTGCC } \\
\text { TTGTACCTTGTGTATCAGGG }\end{array}$ & $\sim 1150$ & Weigl et al., 2012 \\
\hline 0036F/R & $\begin{array}{l}\text { TAGCWGCWGGTAATCAAGA } \\
\text { GCTCCTCCWACWTTRAATT }\end{array}$ & $\sim 9302$ & Zhang et al., 2013 \\
\hline 0038F/R & $\begin{array}{l}\text { TCATATCAYTRACACCACA } \\
\text { GAGGKTATCARCCWGAACG }\end{array}$ & $\sim 9602$ & Zhang et al., 2013 \\
\hline 0040F/R & $\begin{array}{l}\text { GCHCCTTCACAWACTCTAAAWGT } \\
\text { CRTAATAWATTCCTCGTCCTA }\end{array}$ & $\sim 11002$ & Zhang et al., 2013 \\
\hline 0043F/R & $\begin{array}{l}\text { ATYTATAGGGTCTTCTCGTCT } \\
\text { AATATGYACACATCGCCCGTC }\end{array}$ & $\sim 9902$ & Zhang et al., 2013 \\
\hline 0044F/R & $\begin{array}{l}\text { GACGGGCGATRTGTRCATA } \\
\text { CCAGCAGTCGCGGTTATAC }\end{array}$ & $\sim 5302$ & Zhang et al., 2013 \\
\hline 0046F/R & $\begin{array}{l}\text { AGGAGCWTGAATAGGWTTAGA } \\
\text { RTGGCTGAAGTTWAGGCRATA }\end{array}$ & $\sim 10002$ & Zhang et al., 2013 \\
\hline 0049F/R & $\begin{array}{l}\text { ATTTTCYGTATTYGACCCYTC } \\
\text { TCTCGWGAWACATCTCGTCAT }\end{array}$ & $\sim 8302$ & Zhang et al., 2013 \\
\hline 0056F/R & $\begin{array}{l}\text { CTTTYACAATACTAWTWMAC } \\
\text { WAAACTAGGATTAGATACC }\end{array}$ & $\sim 6002$ & Zhang et al., 2013 \\
\hline $0071 F / R^{*}$ & $\begin{array}{l}\text { ATGACTGAAAGCAAGTAT } \\
\text { ATTAGCTGTTAATCGTAC }\end{array}$ & $\sim 750$ & \\
\hline
\end{tabular}

which gives a mismatch with the standard coxl barcode region for Sarcophaga crassipalpis (locus: JN964810) (Meiklejohn et al., 2012) from BOLD (http://www.barcodinglife.org/) and one with locus KT272859, which is stated to be Sarcophaga bullata, but which shows $99.96 \%$ identity in protein-coding genes (PCGs) to the locus NC_026667 (Sarcophaga crassipalpis).

Nineteen mitogenomes of Oestroidea (Table 2) were downloaded from GenBank to reconstruct the phylogeny of Sarcophagidae, with Lucilia cuprina as an outgroup. All 15 genes were aligned separately with MAFFT v 7.3.1 (Katoh \& Standley, 2016), following Kutty et al. (2014). After alignment, all 13 PCGs and two rRNAs were concatenated using SequenceMatrix v 1.7.8 (Meier et al., 2006). Subsequently, PartitionFinder v 2.1.1 (Lanfear et al., 2016) was used to evaluate the best partitioning schemes based on BIC (Bayesian Information Criterion) using the greedy option with branch lengths estimated as "unlinked", with the dataset partitioned by genes. Phylogenetic analyses were conducted using Maximum Likelihood (ML) and Bayesian Inference (BI) as described in Zhang et al. (2016b).

Synonymous and non-synonymous substitution rates (Ks and $\mathrm{Ka}$ ) for each species of each protein-coding gene (PCG) alignment were calculated using DnaSP version 5.10.1 (Librado \& Rozas, 2009), with stop codons and codons with alignment gaps excluded. A plot of pairwise Ka versus Ks for each gene was then constructed using Sigmaplot v 12.5 (Systat Software Inc. California, USA).

\section{RESULTS AND DISCUSSION}

As the control region of $M$. mesomelaena could not be amplified, the small ribosomal RNA gene is incomplete at the 5' end. The nearly-complete mitogenome of $M$. mesomelaena $(14,559 \mathrm{bp}$ ) was submitted to GenBank (Accession Number: KY003227).

The mitogenome contains 13 PCGs, two ribosomal RNA genes (rRNA) and 22 transfer RNA genes (tRNA), with the same locations as generally in Diptera (i.e., Nelson et al., 2012; Zhang et al., 2016b) and ancestral insects (see Fig. 2 in Cameron, 2014) (Table 3, Fig. 3). The overall nucleotide composition exhibits high AT content (76.9\%) similar to other calyptrates (Zhang et al., 2016b).

All PCGs share the start codon of ATT or ATG, except for coxl (TCG), nad3 and nad1 (ATA). Four genes (cox1, cox2, nad5, and nad4) use the incomplete stop codon T, and cytb uses TAG. The remaining eight PCGs have the typical stop codon of TAA.

The selection acting on a gene may be detected by comparing the synonymous (Ks) and non-synonymous (Ka) nucleotide distances between gene sequences (Hurst, 2002). Higher Ka than Ks indicates positive selection, and lower $\mathrm{Ka}$ than $\mathrm{Ks}$ indicates negative selection. The Ka value is obviously lower than the Ks value for all sarcophagid

Table 2. Taxa included in the phylogenetic analyses in this study.

\begin{tabular}{|c|c|c|c|c|}
\hline Family & Subfamily & Species & Locus & Reference \\
\hline \multirow[t]{2}{*}{ Calliphoridae } & Luciliinae & Lucilia cuprina & NC_019573 & Nelson et al., 2012 \\
\hline & Polleniinae & Pollenia rudis & JX̄̄13761 & Nelson et al., 2012 \\
\hline \multirow[t]{13}{*}{ Sarcophagidae } & Sarcophaginae & Sarcophaga melanura & NC_026112 & Zhang et al., 2016a \\
\hline & Sarcophaginae & S. portschinskyi & NC_025574 & Shi et al., 2016 \\
\hline & Sarcophaginae & S. peregrina & NC_023532 & Zhong et al., 2016 \\
\hline & Sarcophaginae & S. impatiens & NC_017605 & Nelson et al., 2012 \\
\hline & Sarcophaginae & S. crassipalpis & NC_026667 & Ramakodi et al., 2015 \\
\hline & Sarcophaginae & S. africa & NC_025944 & Fu et al., 2016 \\
\hline & Sarcophaginae & S. similis & NC_025573 & Yan et al., 2016 \\
\hline & Sarcophaginae & S. albiceps & NC_028413 & Liao et al., 2016 \\
\hline & Sarcophaginae & Ravinia pernix & NC_026196 & Guo et al., 2016 \\
\hline & Sarcophaginae & Boettcheria latisterna & KT-272848 & Junqueira et al., 2016 \\
\hline & Sarcophaginae & B. bisetosa & KT272844 & Junqueira et al., 2016 \\
\hline & Paramacronychiinae & Wohlfahrtia magnifica & KU578263 & Zhang et al., 2016b \\
\hline & Miltogramminae & Mesomelena mesomelaena & KY003227 & present study \\
\hline \multirow[t]{2}{*}{ Tachinidae } & Exoristinae & Elodia flavipalpis & NC_018118 & Zhao et al., 2013 \\
\hline & Dexiinae & Rutilia goerlingiana & NC_019640 & Nelson et al., 2012 \\
\hline \multirow[t]{2}{*}{ Oestridae } & Cuterebrinae & Dermatobia hominis & NC_006378 & Azeredo-Espin et al., 2004 \\
\hline & Hypodermatinae & Hypoderma lineatum & NC_013932 & Weigl et al., 2010 \\
\hline
\end{tabular}




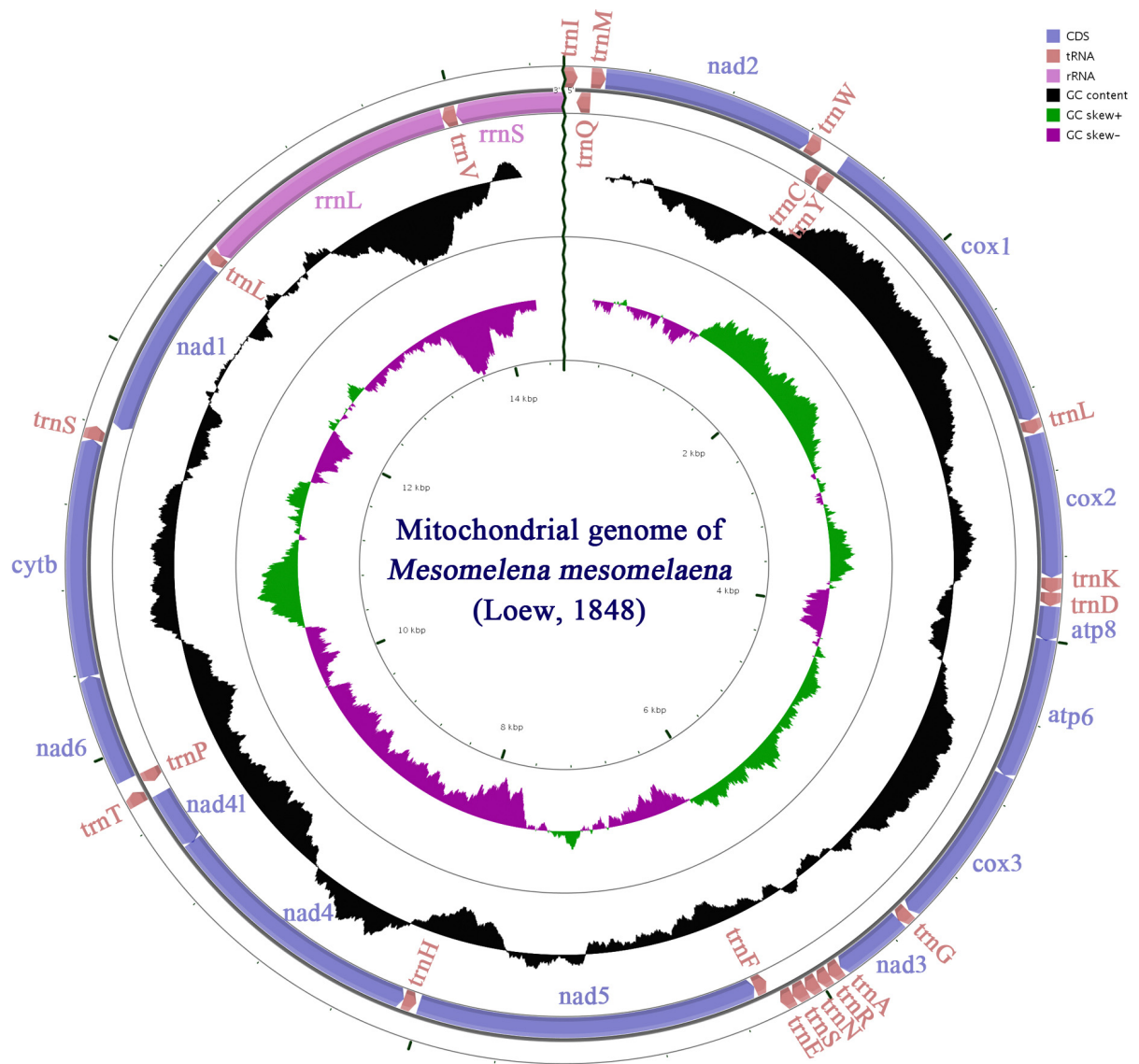

Fig. 3. Mitochondrial genome map of Mesomelena mesomelaena (Loew, 1848).

Table 3. Organization of the mitogenome of Mesomelena mesomelaena (Loew, 1848).

\begin{tabular}{|c|c|c|c|c|c|c|}
\hline \multirow{2}{*}{ Gene } & \multirow{2}{*}{ Product } & \multirow{2}{*}{ Strand } & \multirow{2}{*}{ Location } & \multirow{2}{*}{ Length (bp) } & \multicolumn{2}{|c|}{ Codon } \\
\hline & & & & & Start/Anti & Stop \\
\hline trnl & tRNA-Ile & $\mathrm{N}$ & $1-65$ & 65 & GAT & \\
\hline $\operatorname{trn} Q$ & tRNA-GIn & $\mathrm{J}$ & 63-131 & 69 & TTG & \\
\hline $\operatorname{trnM}$ & tRNA-Met & $\mathrm{N}$ & $131-199$ & 69 & CAT & \\
\hline nad2 & $\mathrm{NADH} 2$ & $\mathrm{~N}$ & $200-1216$ & 1017 & ATT & TAA \\
\hline $\operatorname{trnW}$ & tRNA-Trp & $\mathrm{N}$ & $1215-1282$ & 68 & TCA & \\
\hline $\operatorname{trnC}$ & tRNA-Cys & $\mathrm{J}$ & $1275-1337$ & 63 & GCA & \\
\hline $\operatorname{trn} Y$ & tRNA-Tyr & $\mathrm{J}$ & $1345-1410$ & 66 & GTA & \\
\hline $\operatorname{cox} 1$ & COX1 & $\mathrm{N}$ & $1409-2942$ & 1534 & TCG & $\mathrm{T}$ \\
\hline $\operatorname{trnL}$ & tRNA-Leu & $\mathrm{N}$ & $2943-3008$ & 66 & TAA & \\
\hline $\operatorname{cox} 2$ & cox2 & $\mathrm{N}$ & $3014-3701$ & 688 & ATG & $\mathrm{T}$ \\
\hline trnk & tRNA-Lys & $\mathrm{N}$ & $3702-3772$ & 71 & CTT & \\
\hline $\operatorname{trn} D$ & tRNA-Asp & $\mathrm{N}$ & $3772-3837$ & 66 & GTC & \\
\hline atp8 & ATP8 & $\mathrm{N}$ & $3838-4002$ & 165 & ATT & TAA \\
\hline atp6 & ATP6 & $\mathrm{N}$ & $3996-4673$ & 678 & ATG & TAA \\
\hline $\cos 3$ & cox3 & $\mathrm{N}$ & $4673-5461$ & 789 & ATG & TAA \\
\hline $\operatorname{trnG}$ & tRNA-Gly & $\mathrm{N}$ & $5467-5531$ & 65 & TCC & \\
\hline nad3 & $\mathrm{NADH} 3$ & $\mathrm{~N}$ & $5529-5885$ & 357 & ATA & TAA \\
\hline $\operatorname{trn} A$ & tRNA-Ala & $\mathrm{N}$ & $5887-5951$ & 65 & TGC & \\
\hline $\operatorname{trnR}$ & tRNA-Arg & $\mathrm{N}$ & $5951-6013$ & 63 & TCG & \\
\hline $\operatorname{trnN}$ & tRNA-Asn & $\mathrm{N}$ & $6015-6080$ & 66 & GTT & \\
\hline trns & tRNA-Ser & $\mathrm{N}$ & $6080-6149$ & 70 & GCT & \\
\hline trnE & tRNA-Glu & $\mathrm{N}$ & $6149-6214$ & 66 & TTC & \\
\hline $\operatorname{trnF}$ & tRNA-Phe & $\mathrm{J}$ & $6233-6298$ & 66 & GAA & \\
\hline nad5 & NADH5 & $\mathrm{J}$ & $6299-8018$ & 1720 & ATT & $\mathrm{T}$ \\
\hline $\operatorname{trnH}$ & tRNA-His & $\mathrm{J}$ & 8034-8099 & 66 & GTG & \\
\hline nad 4 & $\mathrm{NADH} 4$ & $\mathrm{~J}$ & $8100-9438$ & 1339 & ATG & $\mathrm{T}$ \\
\hline nad4l & NADH4L & $\mathrm{J}$ & $9432-9728$ & 297 & ATG & TAA \\
\hline $\operatorname{trnT} T$ & tRNA-Thr & $\mathrm{N}$ & $9731-9795$ & 65 & TGT & \\
\hline $\operatorname{trn} P$ & tRNA-Pro & $\mathrm{J}$ & $9796-9860$ & 65 & TGG & \\
\hline nad6 & NADH6 & $\mathrm{N}$ & 9863-10387 & 525 & ATT & TAA \\
\hline cytb & CYTB & $\mathrm{N}$ & $10387-11523$ & 1137 & ATG & TAG \\
\hline trns2 & tRNA-Ser & $\mathrm{N}$ & $11522-11589$ & 68 & TGA & \\
\hline nad1 & NADH1 & $\mathrm{J}$ & $11606-12544$ & 939 & ATA & TAA \\
\hline $\operatorname{trnL}$ & tRNA-Leu & $\mathrm{J}$ & $12555-12619$ & 65 & TAG & \\
\hline$r r n L$ & 16S rRNA & $\mathrm{J}$ & $12620-13941$ & 1322 & & \\
\hline $\operatorname{trnV}$ & tRNA-Val & $\mathrm{J}$ & $13942-14013$ & 72 & TAC & \\
\hline$r r n s$ & 12S rRNA & $\mathrm{J}$ & $14013-14559$ & 547 & & \\
\hline
\end{tabular}




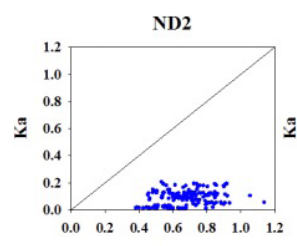

Ks

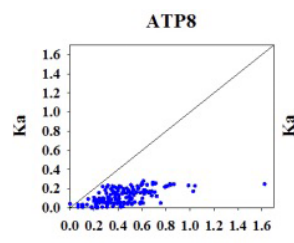

Ks

ND3

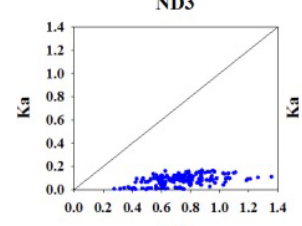

Ks

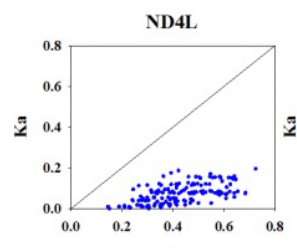

ND1

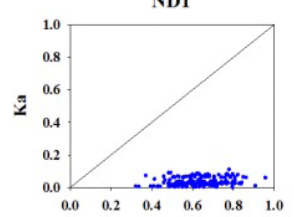

Ks

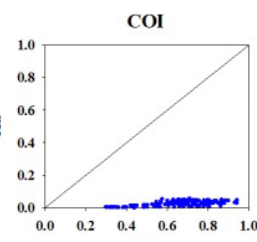

Ks

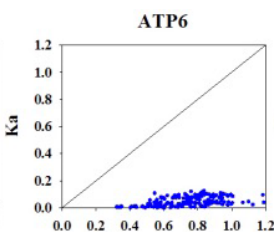

Ks

ND5

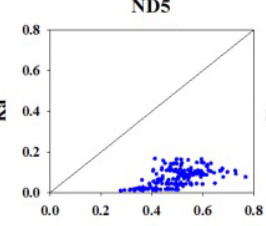

Ks

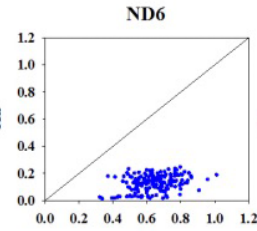

Ks
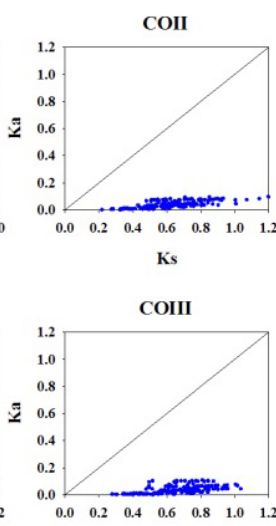

Ks

ND4

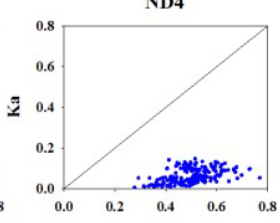

Ks

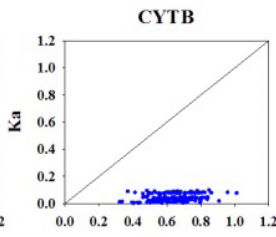

Ks
Fig. 4. Plot of pairwise Ka versus $\mathrm{Ks}$ of the mitochondrial genes of Sarcophagidae.

mitochondrial genes (Fig. 4), except atp8, for which only non-synonymous substitutions between Sarcophaga africa (locus: NC 025944) (Fu et al., 2016) and S. similis (locus: NC_025573) (Yan et al., 2016) were detected. The lower values of $\mathrm{Ka}$ than $\mathrm{Ks}$ indicate negative selection on sarcophagid mitochondrial genes. Specifically, the coxl gene has undergone strong negative selection, indicated by the extremely low Ka value compared to Ks value, which also implies the conservativeness of cox 1 gene.

ML and BI analyses give an identical result, with Sarcophagidae being monophyletic and Sarcophaginae as the sister group to (Paramacronychiinae + Miltogramminae) (Fig. 5). According to previous research the relationship of these three subfamilies is still unresolved. Pape (1996: 9) proposed a probable sister-group relationship between the Paramacronychiinae and Sarcophaginae, based on "the shared possession of a ventrally displaced acrophallus, lack of epiphallus and perhaps spherical female accessory glands", which was corroborated by Giroux et al. (2010) in an explicit morphology-based phylogenetic analysis. This relationship was corroborated by Kutty et al. (2010) using

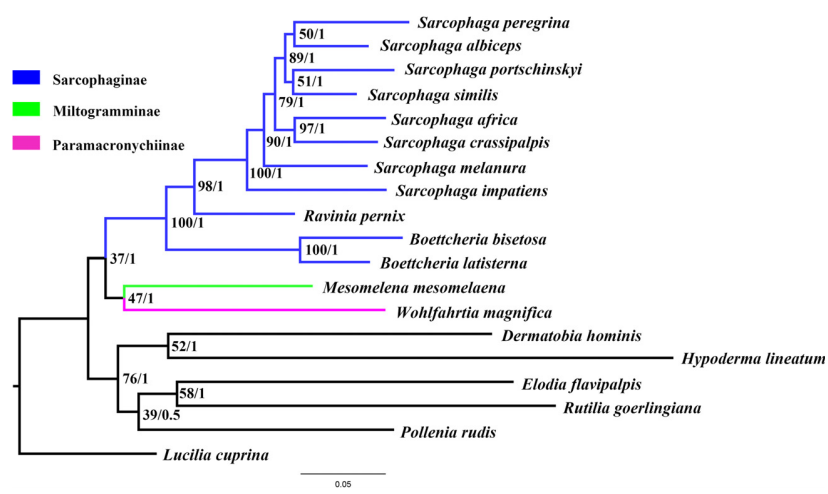

Fig. 5. Phylogeny of Sarcophagidae inferred from a mitochondrial dataset comprising 13 protein-coding genes and 2 rRNA genes. Numbers at nodes are bootstrap values (ML trees) / posterior probabilities (Bayesian trees)

a combination of mitochondrial and nuclear genes, although with low support. However, based on a large-scale (in terms of taxa) molecular phylogeny, Piwczyński et al. (2014) suggest a sister-group relationship of Sarcophaginae to (Paramacronychiinae + Miltogramminae), with Paramacronychiinae being paraphyletic, and Piwczyński et al.'s (2017) results are fully concordant with the above, with each subfamily being monophyletic.

Within the Sarcophaginae, Boettcheria is located as a basal branch, forming a sister group to (Ravinia + Sarcophaga). This is in conflict with morphology-based phylogenies of this subfamily, where Ravinia is subordinate to Boettcheria and Sarcophaga (Pape, 1994; Giroux et al., 2010). The monophyly of Sarcophaga is well supported $(\mathrm{ML}$ bootstrap $=100 ; \mathrm{BI}$ posterior probability $=1)$, but the few taxa sampled and inclusion of only Old World species do not allow the testing of any of the biogeographic hypotheses proposed by Buenaventura et al. (2016) and Buenaventura \& Pape (2017).

This study documents the first mitogenome of Miltogramminae, which contains 37 typical metazoan mitochondrial genes and retains the organization of the ancestral insect mitogenome. The subfamily relationship within Sarcophagidae is reconstructed for the first time as (Sarcophaginae (Paramacronychiinae, Miltogramminae)) based on mitogenomic data.

ACKNOWLEDGEMENTS. This work was supported by the Fundamental Research Funds for the Central Universities (No. JC2015-04), and National Science Foundation of China (No. 31572305).

\section{REFERENCES}

Azeredo-Espin A.M.L., Jungueira A.C.M., Lessinger A.C., Lyra M.L., Torres T.T., da Silva F.R., Meirelles F.V. \& Maia A.A.M. 2004: The complete mitochondrial genome of the human botfly Dermatobia hominis (Diptera: Oestridae). Unpublished poster, ESA Annual Meeting and Exhibition. URL: https://esa.confex.com/esa/2004/techprogram/paper_16801. htm

BÄNZIGER H. \& PAPE T. 2004: Flowers, faeces and cadavers: natural feeding and laying habits of flesh flies in Thailand (Diptera: Sarcophagidae, Sarcophaga spp.). - J. Nat. Hist. 38: 16811698. 
Buenaventura E. \& PAPe T. 2017: Multilocus and multiregional phylogeny reconstruction of the genus Sarcophaga (Diptera, Sarcophagidae). - Mol. Phyl. Evol. 107: 619-629.

Buenaventura E., Whitmore D. \& PAPe T. 2016: Molecular phylogeny of the hyperdiverse genus Sarcophaga (Diptera: Sarcophagidae), and comparison between algorithms for identification of rogue taxa. - Cladistics 32: 109-133.

CAMERoN S.L. 2014: Insect mitochondrial genomics: implications for evolution and phylogeny. - Annu. Rev. Entomol. 59: 95-117.

Cerretti P., Stireman J.O., Pape T., O’Hara J.E., Marinho M.A.T., Rognes K. \& Grimaldi D.A. 2017: First definitive fossil of an oestroid fly (Diptera: Calyptratae: Oestroidea) and the calibration of oestroid divergences. - PLOS ONE 12(8): e0182101, 24 pp.

Fu X., Che K., Zhu Z., Liu J. \& Guo Y. 2016: The complete mitochondria genome of Sarcophaga africa (Diptera: Sarcophagidae). - Mitochondr. DNA (A) 27: 2115-2116.

Giroux M., PAPe T. \& Wheeler T.A. 2010: Towards a phylogeny of the flesh flies (Diptera: Sarcophagidae): morphology and phylogenetic implications of the acrophallus in the subfamily Sarcophaginae. — Zool. J. Linn. Soc. 158: 740-778.

Grant J.R. \& Stothard P. 2008: The CGView Server: a comparative genomics tool for circular genomes. - Nucl. Acid. Res. 36: $181-184$

Guo J., XIE K., Che K., Hu Z. \& Guo Y. 2016: The complete mitochondria genome of Ravinia pernix (Diptera: Sarcophagidae). - Mitochondr. DNA (A) 27: 2069-2070.

Hurst L. 2002: The Ka/Ks ratio: diagnosing the form of sequence evolution. - Trends Genet. 18: 486-489.

Junqueira A.C.M., Azeredo-Espin A.M.L., Paulo D.F., Marinho M.A.T., Tomsho L.P., Drautz-Moses D.I., Purbojati R.W., Ratan A. \& Schuster S.C. 2016: Large-scale mitogenomics enables insights into Schizophora (Diptera) radiation and population diversity. - Sci. Rep. 6: 21762, 13 pp.

Katoh K. \& Standley D.M. 2016: A simple method to control over-alignment in the MAFFT multiple sequence alignment program. - Bioinformatics 32: 1933-1942.

Kutty S.N., Pape T., Wiegmann B.M. \& Meier R. 2010: Molecular phylogeny of the Calyptratae (Diptera: Cyclorrhapha) with an emphasis on the superfamily Oestroidea and the position of Mystacinobiidae and McAlpine's fly. - Syst. Entomol. 35: 614-635.

Kutty S.N., Pont A.C., Meier R. \& PaPe T. 2014: Complete tribal sampling reveals basal split in Muscidae (Diptera), confirms saprophagy as ancestral feeding mode, and reveals an evolutionary correlation between instar numbers and carnivory. Mol. Phylogenet. Evol. 78: 349-364.

Lalitha S. 2000: Primer Premier 5.0. - Biotech. Softw. Internet Rep. 1: 270-272.

Lanfear R., Frandsen P.B., Wright A.M., Senfeld T. \& Calcott B. 2016: PartitionFinder 2: new methods for selecting partitioned models of evolution formolecular and morphological phylogenetic analyses. - Mol. Biol. Evol. 34: 772-773.

Liao H., Yang X., Li Z., Ding Y. \& Guo Y. 2016: The complete mitochondria genome of Parasarcophaga albiceps (Diptera: Sarcophagidae). - Mitochondr. DNA (A) 27: 4696-4698.

Librado P. \& Rozas J. 2009: DnaSP v5: a software for comprehensive analysis of DNA polymorphism data. - Bioinformatics 25: 1451-1452.

LoEw H. 1848: Eine neue europäische Art der Gattung Metopia. - Stettin. Entomol. Ztg. 9: 377-378.

LOPES H.S. 1982: On Eumacronychia sternalis Allen (Diptera, Sarcophagidae) with larvae living on eggs and hatchilings [sic!] of the East Pacific green turtle. - Rev. Bras. Biol. 42: 425-429.

McKillup S.C., McKillup R.V. \& PAPE T. 2000: Flies that are parasitoids of a marine snail: the larviposition behaviour and life cycles of Sarcophaga megafilosia and Sarcophaga meiofilosia. - Hydrobiologia 439: 141-149.

Meier R., Kwong S., Vaidya G. \& NG P.K.L. 2006: DNA Barcoding and taxonomy in Diptera: a tale of high intraspecific variability and low identification success. - Syst. Biol. 55: 715-728.

Meiklejohn K.A., Wallman J.F., Cameron S.L. \& Dowton M. 2012: Comprehensive evaluation of DNA barcoding for the molecular species identification of forensically important Australian Sarcophagidae (Diptera). - Invertebr. Syst. 26: 515525.

Mullen G.R., Trauth S.E. \& Sellers J.C. 1984: Association of a miltogrammine fly, Eumacronychia nigricornis Allen (Diptera: Sarcophagidae), with the brood burrows of Sceloporus undulatus (Latrielle) (Reptilia: Lacertillia). - J. Georgian. Entomol. Soc. 19: 1-6.

Nelson L.A., Lambkin C.L., Batterham P., Wallman J.F., Dowton M., Whiting M.F., Yeates D.K. \& Cameron S.L. 2012: Beyond barcoding: a mitochondrial genomics approach to molecular phylogenetics and diagnostics of blowflies (Diptera: Calliphoridae). - Gene 511: 131-142.

PAPE T. 1994: The world Blaesoxipha Loew, 1861 (Diptera: Sarcophagidae). - Entomol. Scand. (Suppl.) 45: 1-247.

PAPE T. 1996: Catalogue of the Sarcophagidae of the world (Insecta: Diptera). - Mem. Entomol. Int. 8: 1-558.

Pape T., Blagoderov V. \& Mostovski M.B. 2011: Order Diptera Linnaeus, 1758. - Zootaxa 3148: 222-229.

PICKENS G. 1981: The life history and predatory efficiency of $R a$ vinia lherminieri (Diptera: Sarcophagidae) on the face fly (Diptera: Muscidae). - Can. Entomol. 113: 523-526.

PiwczyŃSKi M., SzPILA K. \& PAPE T. 2014: A large-scale molecular phylogeny of flesh flies (Diptera: Sarcophagidae). - Syst. Entomol. 39: 783-799.

Piwczyński M., Pape T., Sikora M., Deja-Sikora E., Akbarzadeh K. \& SzPILA K. 2017: Molecular phylogeny of Miltogramminae (Diptera: Sarcophagidae): implications for classification, systematics and evolution of larval feeding strategies. - Mol. Phyl. Evol. 116: 49-60.

Ramakodi M.P., Singh B., Wells J.D., Guerrero F. \& Ray D.A. 2015: A 454 sequencing approach to dipteran mitochondrial genome research. - Genomics 105: 53-60.

Shi J., Guo Y., Zhang C., Zhou Y., Yan J., LiaO H. \& Zha L. 2016: The complete mitochondrial genome of the flesh fly, Parasarcophaga portschinskyi (Diptera: Sarcophagidae). Mitochondr. DNA (A) 27: 1910-1911.

Spofford M.G., KuRCZewSKI F.E. \& Downes JR W.L. 1989: Nearctic species of Miltogrammini (Diptera: Sarcophagidae) associated with species of Aculeata (Hymenoptera: Vespoidea, Pompiloidea, Sphecoidea, Apoidea). - J. Kans. Entomol. Soc. 62: 254-267.

StUсKY B.J. 2015: Infection behavior, life history, and host parasitism rates of Emblemasoma erro (Diptera: Sarcophagidae), an acoustically hunting parasitoid of the cicada Tibicen dorsatus (Hemiptera: Cicadidae). — Zool. Stud. 54: 30, 17 pp.

Trauth S.E. \& Mullen G.R. 1990: Additional observations on sarcophagid fly infestations of Sceloporus undulatus (Sauria: Iguanidae) egg clutches in Arkansas. - Southwest. Nat. 1: 97-98.

Weigl S., Testine G., Parisi A., Dantas-Torres F., Traversa D., Colwell D.D. \& Otranto D. 2010: The mitochondrial genome 
of the common cattle grub, Hypoderma lineatum. - Med. Vet. Entomol. 24: 329-335.

Wiegmann B.M., Trautwein M.D., Winkler I.S., Barr N.B., Kim J.W., Lambkin C., Bertone M.A., Cassel B.K., Bayless K.M., Heimberg A.M. et AL. 2011: Episodic radiations in the fly tree of life. - Proc. Natn. Acad. Sci. USA 108: 5690-5695.

Yan J., Liao H., Zhu Z., Xie K., Guo Y. \& Cai J. 2016: The complete mitochondria genome of Parasarcophaga similis (Diptera: Sarcophagidae). — Mitochondr. DNA (A) 27: 16421643.

Zhang N.X., Zhang Y.J., Yu G. \& Chen B. 2013: Structure characteristics of the mitochondrial genomes of Diptera and design and application of universal primers for their sequencing. Acta. Entomol. Sin. 56: 398-407 [in Chinese.]

Zhang C., Fu X., Zhu Z., XIE K. \& Guo Y. 2016a: The complete mitochondrial genome sequence of Helicophagella melanura (Diptera: Sarcophagidae). — Mitochondr. DNA (A) 27: 39053906.
Zhang D., Yan L., Zhang M., Chu H., CaO J., Li K., Hu D. \& PAPE T. 2016b: Phylogenetic inference of calyptrates, with the first mitogenomes for Gasterophilinae (Diptera: Oestridae) and Paramacronychiinae (Diptera: Sarcophagidae). - Int. J. Biol. Sci. 5: 489-504.

Zhao Z., Su T., Chesters D., Wang S., Ho S.Y.W., Zhu C., Chen X. \& Zhang C. 2013: The mitochondrial genome of Elodia flavipalpis Aldrich (Diptera: Tachinidae) and the evolutionary timescale of tachinid flies. - PLOS ONE 8: e61814, 15 pp.

Zhong M., Wang X., Liu Q., Wu C. \& Wen J. 2016: The complete mitochondrial genome of the flesh fly, Boettcherisca peregrina (Diptera: Sarcophagidae). - Mitochondr. DNA (A) 27: 106-108.

Received July 6, 2017; revised and accepted October 3, 2017 Published online October 23, 2017 